\title{
Use of second-person pronouns and schizophrenia
}

Andrew R. Watson, Çaǧla Defteralı, Thomas H. Bak, Antonella Sorace, Andrew M. McIntosh,

David G. C. Owens, Eve C. Johnstone and Stephen M. Lawrie

\section{Summary}

A masked analysis of videotaped assessments of people at high genetic risk of schizophrenia revealed that those who subsequently went on to develop schizophrenia used significantly more second-person pronouns. This was evident before diagnosis, at two separate assessments approximately 18 months apart. This supports the view that people who go on to develop schizophrenia may have an abnormality in the deictic frame of interpersonal communication - that is, the distinction between concepts being self-generated or from elsewhere may be blurred prior to the onset of a diagnosis of schizophrenia.

\section{Declaration of interest}

None.
Most speech contains a significant amount of errors, although these are typically corrected by the speaker almost immediately and do not result in the listener failing to understand the message. ${ }^{1}$ The gross abnormalities in psychotic speech, epitomised by formal thought disorder, are characterised by the speaker not having insight into the incomprehensibility of the errors they are making; indeed, it often seems that the person is convinced that the language they are using is completely understandable to the listener. ${ }^{2}$ Studies of language abnormalities in schizophrenia have varied from transcribed analysis of single words ${ }^{3}$ through to observer-rated scales looking at the proportion of time the speech is incomprehensible or disfluent in an interview. ${ }^{4}$ Abnormal use of referents in speech has also been found in schizophrenia ${ }^{5}$ but importantly all these analyses have taken place at different points during the illness, and there has been very little opportunity to analyse the speech of people before they develop schizophrenia. The effects of an acute psychotic episode, of medication, the organisation of services and the response of the person to a diagnosis all may have an effect on the communication styles of people with an established diagnosis. The Edinburgh High Risk Study (EHRS) - and in particular videotaped interviews of some participants - offers the opportunity to prospectively and blindly examine the use of language of a group of people who are at high genetic risk of schizophrenia before they meet diagnostic criteria for psychosis. ${ }^{6}$

\section{Method}

The EHRS has been described in full elsewhere. ${ }^{6}$ Briefly, people at high genetic risk of schizophrenia, from multiply affected families, were identified and a control group from a similar social background was also recruited. Repeated assessments at approximately 18-month intervals were conducted. At each assessment a number of tests were done including magnetic resonance imaging brain scans, psychometric tests and a Present State Examination (PSE) ${ }^{7}$ which was videotaped with the participant's consent. All the interviews were conducted by two researchers with extensive experience using the PSE (E.C.J. and D.C.G.O.). Over the course of the study, a high proportion of participants returned for follow-up assessments: $82 \%$ of the high-risk group and $75 \%$ of the control group. The EHRS split its participants into four groups, based on the PSE: those at high risk who subsequently developed schizophrenia; those who had psychotic symptoms but who did not develop schizophrenia; those at high risk without any psychotic experiences; and controls. In this study, we included a subgroup of the total EHRS population who all had two videotaped assessments in the first 5 years of the study. Table 1 shows the demographic data of the four groups. Owens et $a l^{6}$ details the demographics and symptoms profile of the whole EHRS study. There were no significant differences between the findings in that paper and the sub-sample used in the present study.

From the PSE, a 200-word transcript was taken. Once 200 words were reached, the analysis continued until the end of the answer of that question (mean number of words analysed 202.9). The sample of speech was taken from the first part of the interview, which concerns general physical and mental wellbeing, and was never further than the question regarding obsessional thoughts in the PSE. The median section of the PSE reached was number 7: 'appetite, sleep, retardation, libido.' There was no significant difference in the section reached between the groups or between the two interviewers. The transcriber and rater were masked as to whether the person had psychotic symptoms at the time of the interview or not, just as they were masked to group status and whether or not the person subsequently developed schizophrenia (six individuals did, an average of 943 days (s.e. $=160)$ after the first assessment). The transcripts were scanned a number of times by the rater to identify the parts of speech used. The percentage of the total number of words used for each speech variable was then obtained. The variables obtained were: singular and plural nouns; continuous, past tense and infinitive verbs; pronouns; articles; conjunctives; and errors. Errors were grouped in the analysis and consisted of self-repair, staggers, repeats and pause fillers.

Multivariate analysis of variance was performed to examine the differences between the groups at the participants' first assessment. Repeated measures analysis of variance was performed to examine differences between the groups over time, from first assessment to second assessment. Participant IQ and social class were entered as covariates. Significant results were then examined using one-way ANOVA, as reported below. The significance level was adjusted for multiple tests by the Bonferroni method.

\section{Results}

There were no significant differences between the high-risk group as a whole and the controls on any measure, nor were there significant differences between those within the high-risk group who had experienced psychotic symptoms and those who had not. 


\begin{tabular}{|c|c|c|c|c|}
\hline & \multirow[b]{2}{*}{$\begin{array}{l}\text { Control group } \\
\qquad(n=8)\end{array}$} & \multicolumn{3}{|c|}{ High-risk group } \\
\hline & & $\begin{array}{c}\text { No psychotic } \\
\text { experience }(n=12)\end{array}$ & $\begin{array}{l}\text { Psychotic symptoms, no } \\
\text { schizophrenia }(n=12)\end{array}$ & $\begin{array}{l}\text { Schizophrenia } \\
\quad(n=6)\end{array}$ \\
\hline \multicolumn{5}{|l|}{ Gender, $n$} \\
\hline Male & 4 & 4 & 5 & 4 \\
\hline Female & 4 & 8 & 7 & 2 \\
\hline Age, years: mean (s.d.) & $22.3(2.0)$ & $21.5(3.0)$ & $22.0(3.2)$ & $19.0(1.5)$ \\
\hline Social class, median & 4 & 3 & 4 & 4 \\
\hline National Adult Reading Test, ${ }^{11}$ mean (s.d.) & $102.3(12.0)$ & $102.5(9.5)$ & $98.7(9.22)$ & $103.6(12.7)$ \\
\hline
\end{tabular}

Within the high-risk group, however, those who developed schizophrenia used significantly more second-person pronouns than those who did not $(P=0.005$, d.f. $=1, F=9.4)$. As a percentage of the total words used, those who developed schizophrenia used second-person pronouns $0.5 \%$ of the time and those who did not used them $0.25 \%$ of the time (range $0-1.46$ ). An example indicative of the abnormality is: patient: 'You mentioned . . .'; interviewer: 'No, you were telling me about . . ..

The same pattern was found when the groups were compared across two assessments. Only the use of second-person pronouns within the high-risk group was significant, differing between those who developed schizophrenia and those who did not $(P=0.003$, d.f. $=1, F=11.7)$. There were no significant differences between the high-risk group and controls, and no significant differences between those who had had psychotic symptoms and those who had not.

\section{Discussion}

Pronouns are deictic words that, while having fixed semantic meaning, require consideration of place or time to have specific, denotational meaning. ${ }^{8}$ Repetition of what another person says is not an option when using a second-person pronoun. They place the representative functions of speech, such as describing a table, in the appropriate interpersonal (and time/place) context for accurate communication between speaker and listener. ${ }^{8}$ Difficulty in establishing the difference between 'you' and 'I' leads to this structuring frame of the representative functions of speech being disturbed and can make communication unintelligible. ${ }^{8,9}$ Broadly intact representational memory structure has been described in schizophrenia, with abnormalities found when using words to construct relational interpretations. ${ }^{10}$ Abnormality in the deictic frame has been proposed as a fundamental disturbance in schizophrenia, underlying the blurred boundary between self and other seen across psychotic symptoms. ${ }^{9}$ The abnormal use of pronouns was found at two time points in the study and was consistent despite changes in the symptom profile in both the people who did and those who did not go on to develop schizophrenia. This suggests it reflects a more fundamental abnormality in people with schizophrenia's experience of the world rather than being an association with a specific symptom cluster.

\section{Funding}

This work was funded by the UK Medical Research Council.

Andrew R. Watson, MRCPsych, Division of Psychiatry, University of Edinburgh, Royal Edinburgh Hospital; Çağla Defteralı, MSC, Thomas H. Bak, MD, PhD, Antonella Sorace, MA, PhD, FRSA, FRSE, School of Philosophy Psychology and Language Sciences, University of Edinburgh; Andrew M. McIntosh, David G. C. Owens, MD (Hons), FRCPsych, FRCP (Glas), Eve C. Johnstone, MD, FRCPsych FRCP, FRSE, Stephen M. Lawrie, MD (Hons), FRCPsych Hon, FRCP (Edin), Division of Psychiatry, University of Edinburgh, Royal Edinburgh Hospital, Edinburgh, UK

Correspondence: Dr Andrew Watson, Division of Psychiatry, University of Edinburgh, Kennedy Tower, Royal Edinburgh Hospital, Morningside Place, Edinburgh EH10 5HF, UK. Email: awatson3@nhs.net

First received 8 Apr 2011, final revision 24 Oct 2011, accepted 19 Dec 2011

\section{References}

1 Ferreira F, Patson $\mathrm{N}$. The 'good enough' approach to language comprehension. Lang Linguist Compass 2007; 1: 71-83.

2 Covington MA, He C, Brown C, Naci L, McClain JT, Fjordbak BS, et al. Schizophrenia and the structure of language: the linguist's view. Schizophr Res 2005; 77: 85-98.

3 Thomas P, Kearney G, Napier E, Ellis E, Leudar I, Johnson M. The reliability and characteristics of the brief syntactic analysis. Br J Psychiatry 1996; 168 334-7.

4 Andreasen NC. Scale for the assessment of thought, language, and communication (TLC). Schizophr Bull 1986; 12: 473-82.

5 Champagne-Lavau M, Fossard M, Martel G, Chapdelaine C, Blouin G, Rodriguez JP, et al. Do patients with schizophrenia attribute mental states in a referential communication task? Cogn Neuropsychiatry 2009; 14: 217-39.

6 Owens DGC, Miller P, Lawrie SM, Johnstone, EC. Pathogenesis of schizophrenia: a psychopathological perspective. Br J Psychiatry 2005; 186 386-93.

7 Wing JK, Cooper JE, Sartorius N. The Description and Classification of Psychiatric Symptoms. An Instruction Manual for the PSE and CATEGO Systems. Cambridge University Press, 1974.

8 Buhler K. Sprachtheorie. 1934. Reprinted as Theory of Language: The Representational Function of Language (trans. DF Goodwin). John Benjamins Publishing Company, 1984.

9 Crow TJ. The nuclear symptoms of schizophrenia reveal the four quadrant structure of language and its deictic frame. J Neurolinguistics 2010; 23: 1-9.

10 Titone D, Libben M, Niman M, Ranbom L, Levy D. Conceptual combination in schizophrenia: Contrasting property and relational interpretations. J Neurolinguistics 2007; 20: 92-110.

11 Nelson H, Willison J. National Adult Reading Test. nferNelson, 1991. 